\title{
Small airways function declines after allogeneic haematopoietic stem cell transplantation
}

\author{
S. Lahzami*,\#, R.E. Schoeffel ${ }^{\top}$, V. Pechey ${ }^{+}$, C. Reid ${ }^{+}$, M. Greenwood ${ }^{+}$, C.M. Salome*, \\ N. Berend ${ }^{\star,},{ }^{,}, f$ and G.G. King ${ }^{*}, \uparrow, \delta, f$
}

ABSTRACT: Bronchiolitis obliterans (BO) following allogeneic haematopoietic stem cell transplantation (HSCT) affects peripheral airways. Detection of BO is presently delayed by the low sensitivity of spirometry.

We examined the relationship between peripheral airway function and time since HSCT, and compared it with spirometry and clinical indices in 33 clinically stable allogeneic HSCT recipients. The following measurements were performed: lung function, exhaled nitric oxide, forced oscillatory respiratory system resistance and reactance, acinar (Sacin) and conductive airways ventilation heterogeneity and lung clearance index ( $(\mathrm{Cl})$ measured by multiple breath nitrogen washout. 22 patients underwent repeat visits from which short-term changes were examined.

Median time post HSCT was 12 months. Eight patients were clinically diagnosed as having BO. In multivariate analysis, time since HSCT was predicted by Sacin and forced expiratory volume in $1 \mathrm{~s} \%$ predicted. 20 patients had abnormal Sacin with normal spirometry, whereas none had airflow obstruction with normal Sacin. Sacin and LCl were the only measures to change significantly between two visits, with both worsening. Change in Sacin was the only parameter to correlate with change in chronic graft-versus-host disease grade.

In conclusion, peripheral airways ventilation heterogeneity worsens with time after HSCT. Sacin may be more sensitive than spirometry in detecting $\mathrm{BO}$ at an early stage, which needs confirmation in a prospective study.

KEYWORDS: Airway physiology, airway resistance, exhaled nitric oxide, lung function in disease, obliterative bronchiolitis, stem cell transplantation

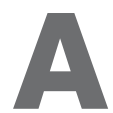

llogeneic haematopoietic stem cell transplantation (HSCT) is a procedure widely used for the treatment of a variety of haematological disorders. Pulmonary complications are a major cause of morbidity and mortality in HSCT recipients, with bronchiolitis obliterans (BO) being the most frequent noninfectious cause ( $2-40 \%$ of all recipients) [1-3]. $\mathrm{BO}$ is a progressive fibrinous obliteration of small airways that is strongly associated with chronic graft-versus-host disease (cGVHD) [1, 3-6], and clinically characterised by the development of airflow obstruction which arises $\geqslant 3$ months after transplantation, as evidenced by spirometry.

Gold standard diagnosis requires transbronchial, thoracoscopic or open lung biopsy, which is rarely performed because of sampling errors, the high degree of immunosuppression often present and risks associated with these diagnostic procedures [7]. Lung volume measurements and expiratory high-resolution computed tomography to detect low-attenuation areas, which suggest gas trapping as a manifestation of airways disease are also useful [8]. Symptoms and signs of airflow obstruction on spirometry do not occur until disease of the small airways is widespread and lesions are more likely to be irreversible [9]. Sensitive and reproducible measures that enable early detection and monitoring of peripheral airway function may allow a better understanding of the pathogenesis and natural history of $\mathrm{BO}$ and may contribute to the development of novel and more effective treatment. The lack of such measures is currently impeding progress in this disease.

Increased exhaled nitric oxide (eNO), presumably representing increased airway inflammation, has recently been reported in early BO syndrome (BOS) in lung transplant recipients [10]. Similarly, changes in single-breath washouts were reported to precede changes in spirometry
AFFILIATIONS

*The Woolcock Institute of Medical Research,

${ }^{5}$ Cooperative Research Centre for Asthma and Airways, Glebe,

"Depts of Respiratory Medicine and, +Haematology, Royal North Shore Hospital, St Leonards, and ${ }^{f}$ The Northern \& Central Clinical Schools, University of Sydney, New South Wales, Australia.

" Service de Pneumologie, Centre Hospitalier Universitaire Vaudois et Université de Lausanne, Lausanne, Switzerland.

\section{CORRESPONDENCE}

S. Lahzami

Service de Pneumologie

Centre Hospitalier Universitaire

Vaudois

Rue du Bugnon 46

1011 Lausanne

Switzerland

E-mail: samir.lahzami@chuv.ch

Received:

Feb 012011

Accepted after revision:

April 112011

First published online:

May 122011

European Respiratory Journal

Print ISSN 0903-1936

Online ISSN 1399-3003 
in a similar cohort [11]. There are no published studies on peripheral airway function in HSCT recipients.

The multiple-breath nitrogen washout (MBNW) test is a measure of peripheral airway function that is highly reproducible [12] and sensitive to peripheral airway dysfunction in smokers who have normal spirometry [12-14]. It provides measurements of ventilation heterogeneity in the lung as a whole (lung clearance index (LCI)), in peripheral airways where gas transport is predominantly convective (Scond) and in more peripheral airways still where gas transport is predominantly diffusive (Sacin) $[15,16]$. The rationale for the use of the MBNW test in this setting is based on the notion that ventilation becomes more uneven and heterogeneous early in peripheral airways disease [17]. Respiratory system resistance $(R \mathrm{rs})$ and reactance $(\mathrm{Xrs})$ measured using the forced oscillation technique (FOT) have also been used as measures of peripheral airway function when using an oscillation frequency of $\leqslant 8 \mathrm{~Hz}$ $[18,19]$. Airway narrowing may increase resistance [20], while airway closure and a more heterogeneous distribution of airway calibres may increase the respiratory system stiffness, and thus increase $X \mathrm{rs}$ in absolute value [21, 22]. In a lung transplant recipient with suspected acute rejection, HAMAKAWA et al. [23] reported a good correlation between FOT measurements and clinical symptoms before and after steroid therapy.

The likelihood of having BO increases not only with time posttransplantation but also with increased age at transplantation, with having had acute and/or cGVHD [3, 24] and with myeloablative conditioning [7]. Moreover, once BO occurs, airflow obstruction progressively worsens in the majority of patients [9, 25]. Thus, we hypothesised that measures of peripheral airway function would be more abnormal with increased time following HSCT. Our primary aims were to determine whether ventilation heterogeneity, $\mathrm{Rrs}, \mathrm{Xrs}$ and $\mathrm{eNO}$, as measurements of peripheral airway function, are related to time post HSCT in a cross-section of HSCT recipients and to determine if they changed over a prospective observational period. The secondary aims were to examine the clinical significance of these measurements by looking at the correlations with spirometry, cGVHD grade and respiratory quality of life.

\section{METHODS}

\section{Study design}

We conducted a prospective observational study of all patients from a single hospital who had received allogeneic HSCT $\geqslant 3$ months previously. Anthropometric characteristics, smoking history and clinical data related to transplantation were collected. Patients had measurements of spirometry, lung volumes, diffusing capacity of the lung for carbon monoxide $(D \mathrm{~L}, \mathrm{CO})$ and $\mathrm{eNO}$ at enrolment and again $\geqslant 3$ months later, depending on their haematological follow-up. Peripheral airway function was measured by the MBNW test and by FOT. A St George Respiratory Questionnaire (SGRQ) was completed as a measure of respiratory quality of life. We examined the relationship between time post-transplantation and peripheral airway function, and related function to SGRQ and CGVHD grade as clinical correlates.

\section{Patients}

Patients were recruited from all allogenic HSCT recipients being managed at the Royal North Shore Hospital, Sydney,
Australia. Subjects had to be clinically stable for $\geqslant 1$ month with neither symptoms of chest infection nor any acute change of respiratory symptoms. Written informed consent was obtained from all subjects and the study was approved by the Human Ethics Review Committee of the Northern Sydney, Central Coast Area Health Service (protocol number 0411-239M).

Anthropometric measurements and smoking history were recorded on the day of testing. Medical history, diagnoses, conditioning regimen, donor human leukocyte antigen match status, cGVHD grade, current or previous episodes of acute GVHD, and presence or absence of hypogammaglobulinaemia were collected from patients' medical records. The staging of acute and cGVHD was performed by a haematologist, according to the International Bone Marrow Transplant Registry (IBMTR) staging system [26] and National Institutes of Health (NIH) consensus guidelines [27], respectively. These guidelines score cGVHD grade as absent, mild, moderate or severe, depending on the number of affected organs and the severity of symptoms. The criteria from the NIH consensus guidelines [27] were also used for the clinical diagnosis of $\mathrm{BO}$, as follows: 1) forced expiratory volume in $1 \mathrm{~s}$ (FEV1)/forced vital capacity (FVC) $<0.7$ and FEV1 $<75 \%$ of predicted; 2 ) radiological, histological or lung volume evidence of air trapping; and 3) absence of respiratory tract infection.

\section{Pulmonary function testing}

Spirometry, lung volumes by plethysmography and DL,CO by single-breath technique were measured according to the American Thoracic Society (ATS) guidelines, using a Sensormedics V-Max Autobox 6200 (Sensormedics Co., Yorba Linda, CA, USA). DL,CO measurements were corrected for haemoglobin concentration. Predicted values were determined from the equations developed by the European Coal and Steel Community (ECSC) [28] for spirometry, and CRAPO et al. [29] for lung volumes and DL,CO. Airflow obstruction was defined by FEV1/FVC lower limit of normal according to the ATS/ European Respiratory Society (ERS) consensus [30].

\section{MBNW test}

A closed circuit, bag-in-box breathing system to deliver $100 \%$ oxygen during inspiration with separate capture of exhaled breath was used to perform the MBNW test, as described previously [12]. The derivation of LCI and indices of ventilation distribution Scond and Sacin were performed as previously reported [12]. Briefly, subjects inhaled 1-L breaths of pure oxygen at $8-12$ breaths $\cdot \mathrm{min}^{-1}$ until mean nitrogen concentration reached $1 / 40$ th of baseline. The washout was performed at least three times. The phase III slope of each breath is normalised to the mean nitrogen concentration (normalised phase III slope; SnIII). Functional residual capacity (FRC) was calculated by the total nitrogen washed out. The cumulative expired volume was normalised for lung size by dividing by FRC, i.e. for a 3-L FRC, one turnover has occurred after three breaths of 1-L size. Scond was the least squares slope of points between turnovers 1.5 and 6, from the plot of SnIII versus turnover (fig. 1). For quality control, any washouts in which an asymptote occurred before turnover 6 and had $\mathrm{r}^{2}<0.85$ were rejected. An SnIII asymptote can occur when conductive ventilation heterogeneity is such that the nitrogen from one part of the lung is completely washed out before 


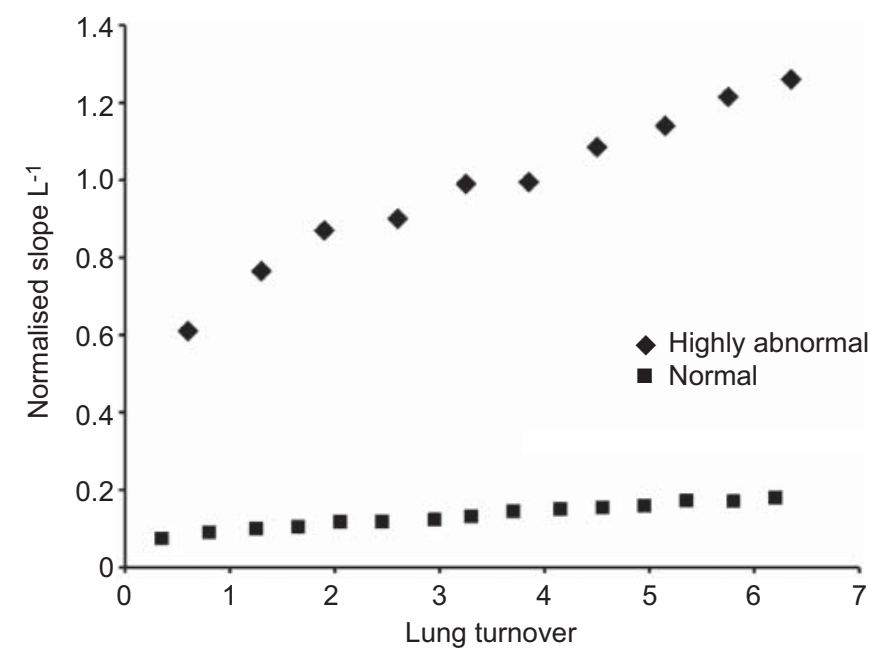

FIGURE 1. Multiple breath nitrogen washout normalised slope curves of two haematopoietic stem cell transplantation recipients with normal and highly abnormal ventilation heterogeneity.

turnover 6 and does not contribute further to gas mixing. This may then confound the Scond parameter.

\section{FOT}

Rrs was measured continuously with FOT at $6 \mathrm{~Hz}$ during 1 min of tidal breathing, with the cheeks supported by the hands. The forced oscillation device provided measurements of flow and pressure at the mouth, and was calibrated using calibration tubes of known resistance. The patients breathed room air through an exhaust port while a $6-\mathrm{Hz}$ oscillation was applied. Flow, differential pressure and mouth pressure were measured as described previously [20]. Mean Xrs and Rrs were calculated as previously reported [31] and expressed as predicted values using the equations of PASKER et al. [32].

\section{eNO}

eNO was measured according to ATS guidelines, using an offline technique. Patients exhaled over 5-15 s at a flow rate of $200 \mathrm{~L} \cdot \mathrm{min}^{-1}$ monitored by a rotameter (Dwyer Flowmeter Model VFASS-25; AMBIT Instruments Pty Ltd, Parramatta, Australia), into a nitric oxide impermeable polyethylene bag (Scholle Industries Pty Ltd, Elisabeth West, Australia). A chemiluminescence analyser (Thermo Environmental Instruments Model 42C; Thermo Environmental Instruments Inc., Franklin, MA, USA) was used to analyse the exhaled gas. Our laboratory upper limit of normal is $13 \mathrm{ppb}$.

\section{Data analysis}

Results are expressed as mean $\pm \mathrm{SD}$ or median and range depending on the distribution of data. Where possible, the distributions of data were normalised via logarithmic or square root transformation. Depending on final data distribution, univariate correlations were determined using either Pearson's (r) or Spearman's (rs) correlation analysis. Multivariate linear regression analyses were used to determine the independent relationships between peripheral airway function, SGRQ scores and duration post HSCT. Measured parameters were corrected for confounding factors, such as age, sex and smoking, by firstly determining their effects as independent variables in a multivariate linear regression. The resultant residuals from this regression were then used in subsequent correlations and regression models. The proportion of patients who had abnormal Sacin was determined on uncorrected data since this is consistent with clinical practice. Paired t-tests or Wilcoxon signed rank test were used to compare measured parameters between two visits, depending on the data distribution of these differences. The method of Holm [33] was used to correct the level of significance for multiple univariate correlations.

\section{RESULTS}

A total of 40 HSCT survivors were identified from Royal North Shore Hospital's transplanted cohort, from which 34 participated in the study. One patient was excluded because of a severe extrapulmonary restrictive syndrome due to severe sclerodermatous GVHD. 33 patients were included in the analyses; their anthropometric characteristics, smoking history and clinical data related to HSCT are presented in table 1. All but four patients were receiving immunosuppression in various combinations of prednisone, cyclosporine, mycophenolate mofetil, tacrolimus and azathioprine. Based on NIH consensus criteria [27], eight (24\%) patients were clinically diagnosed as having BO. The pre-transplant FEV1 was $96 \pm 10 \%$ pred compared with $87 \pm$ $20 \%$ pred at the time of first MBNW testing. The median time post-transplantation was 12 months (range 3-73). Two patients had several allogeneic HSCTs, and time post-transplantation was calculated from the date of the first transplant.

Results of pulmonary function, MBNW test, FOT and eNO measurements are shown in table 2. One patient could not perform the MBNW test because of an inability to use the mouthpiece due to severe mouth GVHD. To illustrate the wide spectrum of ventilation heterogeneity measured by MBNW in this population, normalised slope curves of two patients with normal and highly abnormal ventilation heterogeneity are shown in figure 1. No individual washouts were rejected based on the presence of an asymptote.

\section{Correlations between airway function and time post- transplant}

Correlations between measured parameters and time posttransplant are shown in table 3. FEV1, FVC and residual volume (RV)/total lung capacity (TLC) in \% pred, as well as LCI and Sacin were significantly correlated with time posttransplant in univariate analysis. Forced expiratory volume at $25-75 \%$ of FVC \% pred, Xrs \% pred and Scond had borderline correlations with time post-transplant since they were no longer significant after removing the two patients with highest measured values or longest time post-transplant. FEV1/FVC as absolute values and as \% pred, TLC \% pred, DL,CO \% pred, Rrs $\%$ pred and eNO were not related to time post-transplant.

Age, sex, body mass index (BMI), conditioning regimen (myeloablative versus nonmyeloablative) and smoking history were assessed as potential confounding factors for all small airways measurements. Sacin was correlated with age and smoking history and after correction for these, the correlation between Sacin and time post-transplant remained highly significant ( $r=0.55, p=0.001$; fig. 2). Corrected Sacin was used in subsequent analyses. None of the other measurements were related to any of these potential confounders. 


\begin{tabular}{|c|c|c|}
\hline TABLE 1 & \multicolumn{2}{|c|}{$\begin{array}{l}\text { Clinical characteristics of haematopoietic stem } \\
\text { cell transplantation (HSCT) recipients at time of } \\
\text { testing }\end{array}$} \\
\hline Subjects $n$ & & 33 \\
\hline Age yrs & & $47 \pm 15$ \\
\hline Sex male & & $22(67)$ \\
\hline BMI $\mathbf{k g} \cdot \mathrm{m}^{-2}$ & & $24.7 \pm 4.5$ \\
\hline Smoking his & ory pack-yrs & $1(0-60)$ \\
\hline Time post $\mathrm{H}$ & CT months & $12(3-73)$ \\
\hline \multicolumn{3}{|c|}{ Diagnosis } \\
\hline $\mathrm{AML}$ & & $11(33)$ \\
\hline $\mathrm{CML}$ & & $1(3)$ \\
\hline ALL & & $5(15)$ \\
\hline CLL & & $1(3)$ \\
\hline Lymphoma & & $6(18)$ \\
\hline Multiple my & loma & $3(9)$ \\
\hline Aplastic an & emia & $3(9)$ \\
\hline Myelofibros & & $1(3)$ \\
\hline Myelodyspl & & $2(6)$ \\
\hline \multicolumn{3}{|c|}{ Donor HLA status } \\
\hline HLA-match & d related & $30(91)$ \\
\hline HLA-misma & ched related & $2(6)$ \\
\hline HLA-match & d unrelated & $1(3)$ \\
\hline \multicolumn{3}{|c|}{ Conditioning regimen } \\
\hline Myeloablati & & $14(42)$ \\
\hline Nonmyeloa & lative & $19(58)$ \\
\hline Total body ir & adiation & $6(18)$ \\
\hline Hypogamma & lobuminaemia & $14(42)$ \\
\hline \multicolumn{3}{|c|}{ Acute GVHD } \\
\hline Past episoc & & $15(45)$ \\
\hline Active & & $0(0)$ \\
\hline Unknown & & $3(9)$ \\
\hline \multicolumn{3}{|c|}{ Chronic GVHD grade } \\
\hline 0 & & $12(36)$ \\
\hline 1 & & $10(30)$ \\
\hline 2 & & $6(18)$ \\
\hline 3 & & $2(6)$ \\
\hline Unknown & & $3(9)$ \\
\hline
\end{tabular}

Data are presented as mean $\pm \mathrm{SD}, \mathrm{n}(\%)$, or median (range), unless otherwise stated. BMI: body mass index; AML: acute myeloid leukaemia; CML: chronic myeloid leukaemia; ALL: acute lymphoblastic leukaemia; CLL: chronic Iymphocytic leukaemia; HLA: human leukocyte antigen; GVHD: graft-versushost disease.

To determine which measures of airway function were independently related to time post-transplant, a backwards, stepwise multiple linear regression analysis was performed, including all significant parameters from the univariate analyses, corrected for confounding factors where applicable. The time post-transplant was predicted independently by both Sacin (partial $\mathrm{r}^{2}=0.18, \mathrm{p}=0.04$ ) and $\mathrm{FEV} 1 \%$ pred (partial $\mathrm{r}^{2}=0.24, \mathrm{p}=0.02 ; \mathrm{p}<0.001$ for overall model).

As age at transplant has also been found to be associated with the development of BO [24], we looked for correlations with measured lung function parameters. Sacin was the only parameter to correlate with age at transplant ( $\mathrm{r}_{\mathrm{s}}=0.50, \mathrm{p}=0.004$ ). After correction for smoking history this correlation was still

\begin{tabular}{|c|c|c|}
\hline TABLE 2 & \multicolumn{2}{|c|}{$\begin{array}{l}\text { Pulmonary and peripheral airway function of } 33 \\
\text { haematopoietic stem cell transplantation } \\
\text { recipients }\end{array}$} \\
\hline \multicolumn{3}{|c|}{ Pulmonary functions } \\
\hline FEV $1 \%$ pr & & $87 \pm 20$ \\
\hline FVC \% pre & & $94 \pm 17$ \\
\hline $\mathrm{FEV}_{1} / \mathrm{FVC}$ & & 80 (45-89) \\
\hline FEF25-75\% & pred & $68 \pm 29$ \\
\hline TLC \% pre & & $96 \pm 10$ \\
\hline RV/TLC \% & & $100(79-165)$ \\
\hline$D \mathrm{~L}, \mathrm{CO} \% \mathrm{p}$ & & $73 \pm 19$ \\
\hline \multicolumn{3}{|c|}{ MBNW } \\
\hline $\mathrm{LCl}$ & & $12.1(8.0-22.2)$ \\
\hline Scond $\mathrm{L}^{-1}($ & $<0.04)$ & $0.07 \pm 0.03$ \\
\hline Sacin $L^{-1}(\Lambda$ & $0.13)$ & $0.24(0.08-1.72)$ \\
\hline \multicolumn{3}{|c|}{ FOT } \\
\hline Rrs \% prec & & $118 \pm 31$ \\
\hline Xrs \% pred & & $153(9-997)$ \\
\hline eNO ppb & & $7.2(5.1-14.1)$ \\
\hline SGRQ total & ore & $26(0-46)$ \\
\hline Symptoms & core & $14(0-64)$ \\
\hline Activity scc & & 35 (0-93) \\
\hline Impact scc & & $6(0-44)$ \\
\hline
\end{tabular}

Data are presented as mean \pm SD or median (range). FEV1: forced expiratory volume in $1 \mathrm{~s}$; FVC: forced vital capacity; FEF25-75\%: forced expiratory volume at $25-75 \%$ of FVC; TLC: total lung capacity; RV: residual volume; $D L, C O$ : diffusing capacity of the lung for carbon monoxide; MBNW: multiple breath nitrogen washout; FOT: forced oscillation technique; LCl: lung clearance index; Scond: index of conductive airways heterogeneity; Sacin: index of diffusive airways heterogeneity; $\mathrm{N}$ : upper limit of normal; Rrs: respiratory system resistance; Xrs: respiratory system reactance; eNO: exhaled nitric oxide; SGRQ: St George's Respiratory Questionnaire.

significant $\left(\mathrm{r}_{\mathrm{s}}=0.41, \mathrm{p}=0.02\right)$. However, in a multivariate analysis with time post-transplant and age at transplant, time post-transplant was the sole independent predictor of Sacin.

\section{Correlations between measured parameters}

There were significant interrelationships between peripheral airway function and both spirometry and lung volumes measurements. FEV1 \% pred correlated inversely with corrected Sacin $(r=-0.50, p=0.004)$, Scond $(r=-0.68, p<0.0001)$, LCI $(\mathrm{r}=-0.69, \mathrm{p}<0.0001)$ and $X \mathrm{rs} \%$ pred $(\mathrm{r}=-0.54, \mathrm{p}=0.001) . \mathrm{RV} /$ TLC $\%$ pred correlated with Scond $(\mathrm{r}=0.54, \mathrm{p}=0.002)$ and LCI $(\mathrm{r}=0.43, \mathrm{p}=0.01) .20(61 \%)$ patients without airflow obstruction on spirometry (FEV1/FVC $>$ lower limit of normal) had abnormal Sacin (using an upper limit of normal of $0.13 \mathrm{~L}^{-1}$ ) [12], whereas none had airflow obstruction with a normal Sacin (fig. 3). There were five patients who had gas trapping on static lung volumes (RV/TLC $>120 \%$ pred), all of whom had abnormal Sacin, while $20(61 \%)$ patients who had no gas trapping (RV/TLC $<120 \%$ pred) had abnormal Sacin. The remaining eight patients had normal RV/TLC and Sacin.

\section{Clinical correlates}

$S G R Q$

SGRQ total score was significantly correlated with time posttransplantation $(\mathrm{r}=0.48, \mathrm{p}=0.006)$ but was unrelated to age, 
TABLE 3 Correlations between measured parameters and time post haematopoietic stem cell transplantation

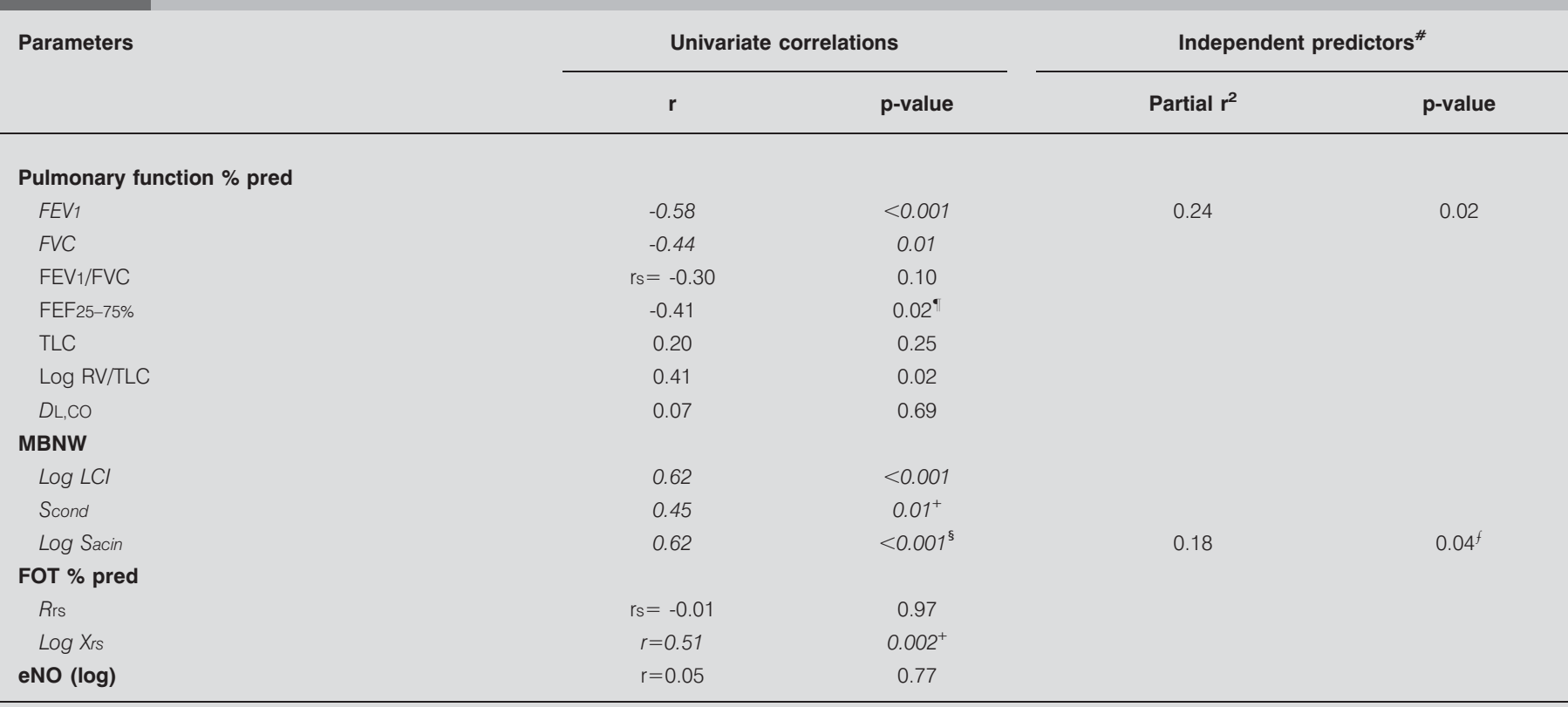

FEV1: forced expiratory volume in $1 \mathrm{~s}$; FVC: forced vital capacity; FEF25-75\%: forced expiratory volume at 25-75\% of FVC; TLC: total lung capacity; RV: residual volume $\mathrm{DL}, \mathrm{CO}$ : diffusing capacity of the lung for carbon monoxide; MBNW: multiple breath nitrogen washout; LCl: lung clearance index; Scond: index of conductive airways heterogeneity; Sacin: index of diffusive airways heterogeneity; FOT: forced oscillation technique; Rrs: respiratory system resistance; Xrs: respiratory system reactance; eNO: exhaled nitric oxide. ${ }^{\#}$ : independent predictors of time post transplant in multiple regression model including significant parameters (in italics) from univariate analyses; ": insignificant after removing the two patients with longest time post-transplant; ${ }^{+}$: insignificant after removing the two patients with highest measured values; s: after correction for age and smoking history (confounding factors), the correlation was still highly significant $(r=0.55, p=0.001) ;{ }^{f}$ : Sacin corrected for confounding factors was used in the multiple regression model. Italics indicates significant univariate correlations after correction for multiple comparisons

sex, BMI, or smoking history. SGRQ total score was significantly correlated with FEV1 \% pred $(r=-0.50, p=0.004)$, RV/ TLC $\%$ pred $(\mathrm{r}=0.37, \mathrm{p}=0.04)$, Scond $(\mathrm{r}=0.55, \mathrm{p}=0.001)$ and LCI $(\mathrm{r}=0.59, \mathrm{p}<0.001)$ but not to corrected Sacin. In multivariate analysis, LCI was the only independent predictor of SGRQ total score.

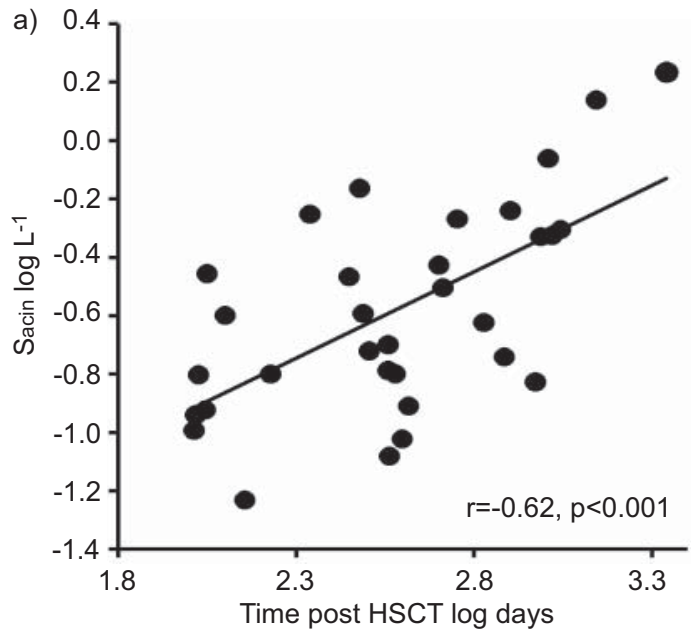

cGVHD grade

cGVHD grade was related to time post-transplantation $\left(r_{s}=0.55, p=0.002\right)$ and SGRQ total score $(r s=0.40, p=0.03)$. Corrected Sacin was the sole airway function measurement to correlate with cGVHD grade ( $\mathrm{r}=0.41, \mathrm{p}=0.03$ ) and was not related to the conditioning regimen (myeloablative versus

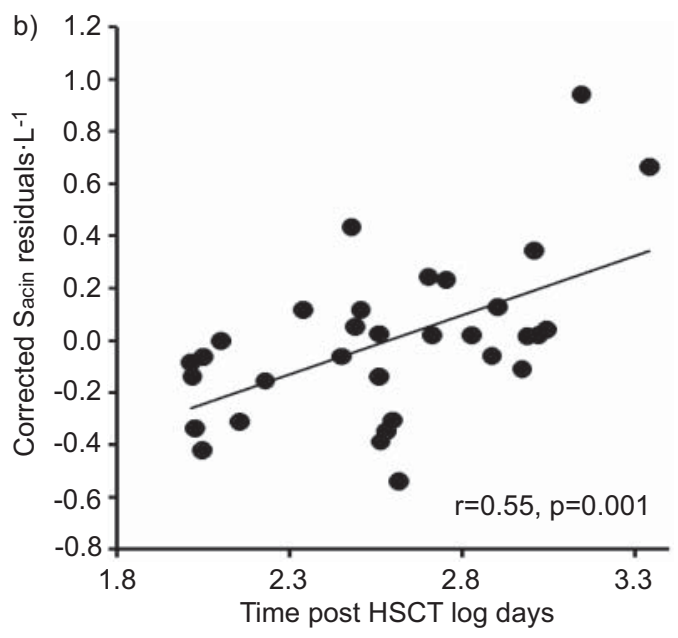

FIGURE 2. Correlation between acinar airways ventilation heterogeneity (Sacin) and time post haematopoietic stem cell transplantation (HSCT). a) Sacin uncorrected for confounding factors. b) Sacin corrected for age and smoking history 


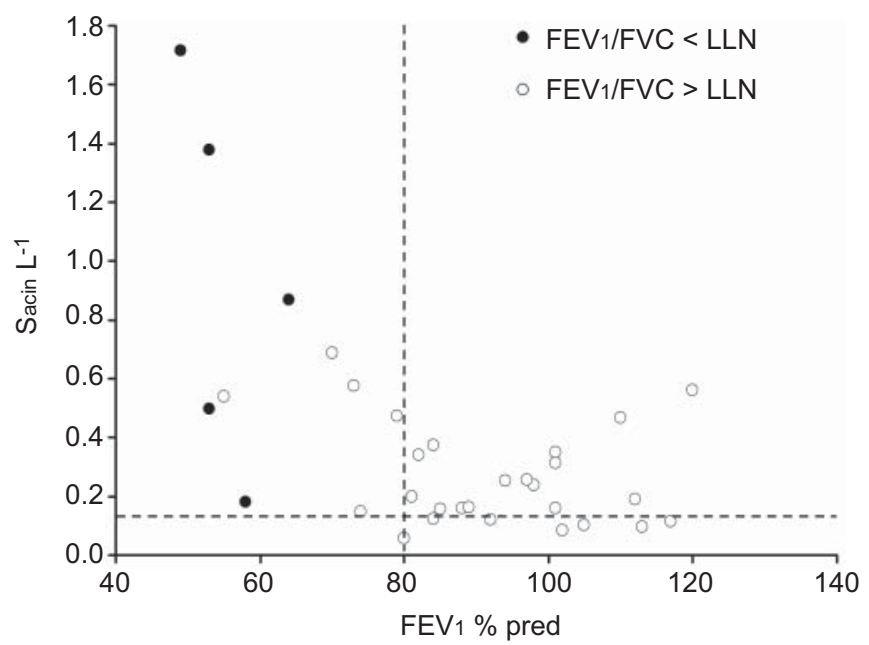

FIGURE 3. Acinar airways ventilation heterogeneity (Sacin) versus airflow obstruction on spirometry in haematopoietic stem cell transplantation (HSCT) recipients. The horizontal dashed line represents the upper limit of normal for Sacin [12], and the vertical dashed line represents lower limit of normal for forced expiratory volume in $1 \mathrm{~s}$ (FEV1) \% predicted. 20 patients had an abnormal Sacin without airflow obstruction on spirometry, whereas no patient had a normal Sacin with an abnormal FEV1/forced vital capacity (FVC). LLN: lower limit of normal according to American Thoracic Society/European Respiratory Society consensus [30].

nonmyeloablative), presence of hypogammaglobulinaemia, or previous episode of acute GVHD.

\section{Longitudinal results (repeat visits)}

A repeat visit was obtained in 22 of the 33 HSCT recipients and was performed $10 \pm 6$ months after the first visit. The remainder 11 patients without repeat visits either could not be contacted or were unable to attend for lung function, while two had died. Changes in measured parameters between the initial and second tests are shown in table 4. Sacin and LCI were the only parameters to change significantly between the two tests, both worsening over time. Change in Sacin (in absolute value and in \% change) was the only parameter to correlate with change in cGVHD grade over the period of follow-up $\left(\mathrm{rs}_{\mathrm{s}}=0.63\right.$, $\mathrm{p}=0.003$ and $\mathrm{rs}=0.65, \mathrm{p}=0.002$, respectively; fig. 4). Change in Sacin was neither correlated with change in FEV1 \% pred $(\mathrm{r} s=0.11, \mathrm{p}=0.65)$, change in RV/TLC $\%$ pred $\left(\mathrm{r}_{\mathrm{s}}=-0.06\right.$, $p=0.80)$, nor with change in any other measured parameters. Change in SGRQ total score between tests was not correlated with change in any physiological measurement.

\section{DISCUSSION}

In this prospective observational study of allogeneic HSCT recipients, we showed that peripheral airway function as measured by Sacin (an index of ventilation heterogeneity in the peripheral airways where gas movement is by diffusion) is worse the longer the time post-transplant. Sacin and FEV1 \% pred were independently related to the time since transplant. Ventilation heterogeneity also correlated with clinical parameters in that Sacin was the sole predictor of cGVHD grade, and LCI independently correlated with SGRQ. A significant number of patients had abnormal Sacin but had normal spirometry. The longitudinal data confirmed that Sacin and LCI change over time, with the change in Sacin correlating with

\begin{tabular}{|c|c|c|c|}
\hline \multirow{2}{*}{$\begin{array}{l}\text { TABLE } 4 \\
\text { Parameters }\end{array}$} & \multicolumn{3}{|c|}{$\begin{array}{l}\text { Repeat visits }{ }^{\#} \text { in } 22 \text { haematopoietic stem cell } \\
\text { transplantation recipients: changes in measured } \\
\text { parameters }\end{array}$} \\
\hline & 1st visit & 2nd visit & p-values \\
\hline \multicolumn{4}{|c|}{ Pulmonary function } \\
\hline FEV1 \% pred & $88 \pm 15$ & $85 \pm 21$ & 0.27 \\
\hline FVC \% pred & $95 \pm 15$ & $94 \pm 18$ & 0.76 \\
\hline FEV $1 / F V C \%$ & $78(67-87)$ & $74(47-85)$ & 0.08 \\
\hline FEF25-75\% \% pre & $68 \pm 26$ & $62 \pm 29$ & 0.09 \\
\hline TLC \% pred & $95 \pm 10$ & $97 \pm 10$ & 0.12 \\
\hline RV/TLC \% pred & $99(71-138)$ & $97(73-165)$ & 0.62 \\
\hline$D\llcorner, \mathrm{CO} \%$ pred & $72 \pm 14$ & $73 \pm 17$ & 0.68 \\
\hline \multicolumn{4}{|l|}{ MBNW } \\
\hline $\mathrm{LCl}$ & $11.6 \pm 2.5$ & $13.5 \pm 3.5$ & 0.003 \\
\hline Scond $\mathrm{L}^{-1}$ & $0.06(0.02-0.17)$ & $0.07(0.02-0.24)$ & 0.21 \\
\hline Sacin $\mathrm{L}^{-1}$ & $0.28(0.06-0.69)$ & $0.41(0.08-1.07)$ & 0.007 \\
\hline \multicolumn{4}{|l|}{ FOT \% pred } \\
\hline Rrs & $113(77-187)$ & $103(73-259)$ & 0.50 \\
\hline Xrs & $151(9-792)$ & $172(47-788)$ & 0.37 \\
\hline eNO ppb & $7.5(4.7-40.1)$ & $6.4(3.6-16)$ & 0.46 \\
\hline SGRQ total scor & $15(0-40)$ & $17(1-63)$ & 0.23 \\
\hline Symptoms scor & $21(0-73)$ & $17(0-68)$ & 0.93 \\
\hline Activity score & $29 \pm 25$ & $33 \pm 27$ & 0.45 \\
\hline Impact score & $7(0-22)$ & $6(0-59)$ & 0.19 \\
\hline cGVHD grade & $0(0-3)$ & $1(0-3)$ & 0.38 \\
\hline
\end{tabular}

Data are presented as mean \pm SD or median (range), unless otherwise stated. FEV1: forced expiratory volume in $1 \mathrm{~s}$; FVC: forced vital capacity; FEF25-75\%: forced expiratory volume at $25-75 \%$ of FVC; TLC: total lung capacity; RV residual volume; $D \mathrm{~L}, \mathrm{CO}$ : diffusing capacity of the lung for carbon monoxide: MBNW: multiple breath nitrogen washout; LCl: lung clearance index; Scond: index of conductive airways heterogeneity; Sacin: index of diffusive airways heterogeneity; FOT: forced oscillation technique; Rrs: respiratory system resistance; Xrs: respiratory system reactance; eNO: exhaled nitric oxide SGRQ: St George's Respiratory Questionnaire; CGVHD: chronic graft-versushost disease. ${ }^{\#}$ : the second visits were performed $10 \pm 6$ months after the first visits; " : paired t-test or Wilcoxon signed rank test depending on the distribution of the differences.

the change in cGVHD grade. We speculate that there may be an ongoing process in HSCT survivors affecting peripheral airway function even when spirometry is normal. $\mathrm{BO}$ is believed to be a lung manifestation of CGVHD, and, given the relationship between Sacin and CGVHD stage in the present study, changes in Sacin may, in part, be due to BO.

Spirometric obstruction may develop in up to $26 \%$ of patients after allogeneic $\operatorname{HSCT}[1,2,25,34,35]$ with the main risk factors for obstruction being cGVHD and busulfan $[3,25]$ and myeloablative pre-conditioning [7]. Although most of the obstruction occurs within the first year, there is an annual incidence of $\sim 1-3 \%[3,24]$. Although biopsy proof of $\mathrm{BO}$ may be obtained in only $50 \%$ of patients for various clinical reasons [3], the development of obstruction is often assumed to be due to $\mathrm{BO}$ in the absence of other identifiable causes $[2,3,7,24,25]$. Our findings of worse small airways function over time following HSCT suggest that future studies should be carried out to examine the time course of changes in small airways 


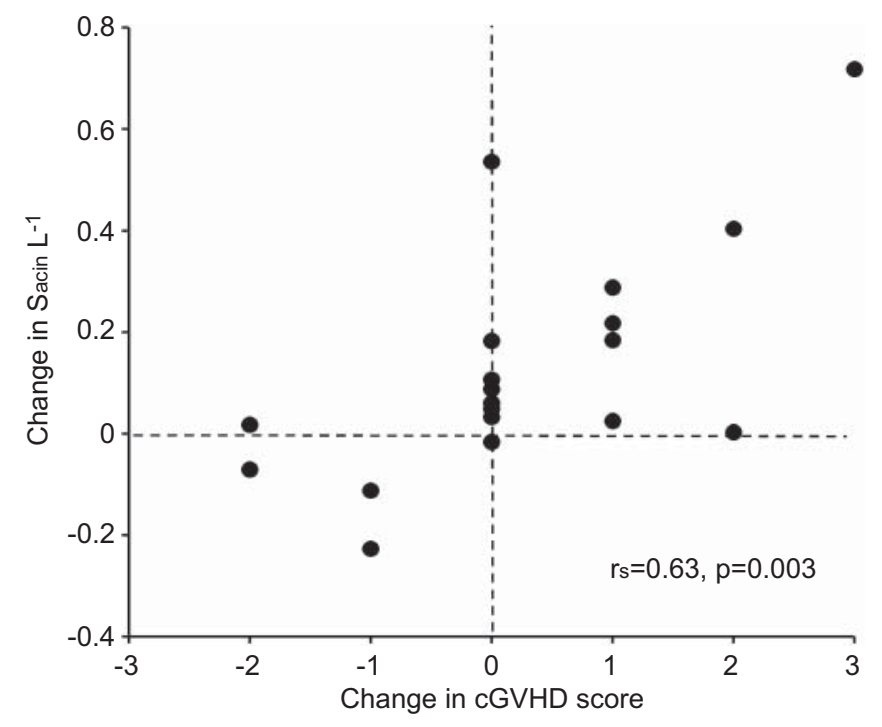

FIGURE 4. Repeat visits. Correlation between change in acinar airways ventilation heterogeneity (Sacin) and change in chronic graft-versus-host disease (cGVHD) grade.

function from pre-transplantation onwards. If the changes in small airways function prove to be predictive of subsequent spirometric obstruction, this would have clinical implications because of the strong association between spirometric obstruction and mortality $[1,2,6,24]$.

The present study is the first systematic analysis of peripheral airway function using both the MBNW test and FOT in an unselected cohort of HSCT recipients, with and without respiratory symptoms. The MBNW test parameters LCI, Scond and Sacin reflect ventilation heterogeneity in specific zones of the lung. The LCI is a global measure, while Scond and Sacin represent the small conducting airways zone and the diffusive gas transport zone, respectively $[15,16]$. Histologically, BO is a process affecting membranous and respiratory bronchioles $[36,37]$, which theoretically is in the region of diffusive gas mixing represented by Sacin. Using heliox maximal expiratory flow-volume curves in five allogeneic bone marrow transplant recipients with severe obstruction, CHAN et al. [38] suggested that the site of obstruction was in the peripheral airways. However, histopathological correlation is absent from the present study and is therefore an area requiring future study.

It is probable that processes other than BO might have affected small airways function, given the myriad of complications that commonly occur in these patients. To minimise this risk, all the patients were tested beyond 3 months post-transplant (when chronic BO also starts to occur), were clinically stable and had no current respiratory infection. Moreover, correlations between peripheral airway parameters were corrected for potential confounding factors such as age, smoking history and conditioning regimen. We found that age at transplant correlated with Sacin. This suggests that Sacin could be increased due to the normal ageing process and/or due to an increased risk of GVHD-related peripheral airway damage with increasing age [24]. It was therefore necessary to correct for age, to determine the effects of processes occurring after the transplant alone. In terms of immunosuppression, all but four of the
33 patients were receiving it and in varying combinations, which meant that we were unable to examine its potential effects on Sacin.

Management of GVHD following HSCT requires continuous monitoring of all organ systems. Sufficient suppression of cGVHD to protect organ systems has also to be balanced against the beneficial anti-tumour effects. BO may result from cGVHD and other potential causes. The significant correlation between Sacin and cGVHD grade is consistent with this relationship. However, because of the low sensitivity of spirometry, BO is presently detected late in the evolution of the disease, when airway obstruction may be less likely to be reversible. Since a significant number of patients had abnormal Sacin with normal spirometry, MBNW may be useful for monitoring lung function in HSCT recipients. Similarly ventilation heterogeneity measured by single-breath gas washout in lung transplant recipients became abnormal before obstruction was evident on spirometry, suggesting possible utility for early detection of BOS [10,39]. Given the identical pathology of BO in HSCT and lung transplant recipients [40], single-breath washout may also have clinical utility in HSCT follow-up.

Measurements of lung mechanics appear to be insensitive to peripheral airways disease in this population. Rrs is a measurement of frictional pressure loss in airways, while reactance represents the compliance of the respiratory system. Although $R \mathrm{rs}$ is increased and $\mathrm{Xrs}$ is decreased at low frequencies in small airways disease, neither are specific markers [18, 41]. We found no correlation between time post-transplantation and Rrs, while the correlation with $X$ rs was driven by the two highest values. The very large range of $X$ rs values in our cohort could reflect high inter-individual variability related to unidentified factors, which might have been responsible for its lack of significant correlations with clinical parameters. The area under the reactance versus frequency curve from multifrequency data could be a worthwhile parameter to examine in future studies. In bilateral lung transplant recipients, BOS is associated with stiffer lungs in terms of both static compliance and the exponential constant K [39]. Interestingly, increased lung stiffness is also associated with greater ventilation heterogeneity even when spirometry is normal [39], which is consistent with the presence of subclinical BO.

Exhaled NO is an established marker of lung inflammation but has never been studied systematically in allogeneic HSCT recipients. In our study, there was no correlation between eNO and time post-transplant, and the vast majority of our patients had values within the normal range $(<13 \mathrm{ppb})$. In a mouse model, eNO was elevated following allogeneic transplantation [42] but its relation to $\mathrm{BO}$ in humans is unclear. Other factors unrelated to $\mathrm{BO}$, such as atopy or conditioning-related lung injury could affect $\mathrm{eNO}$ and make any relationships hard to detect.

Respiratory quality of life decreased over time post HSCT due predominantly to an increase in the symptoms score. There was no change in quality of life over the follow-up period, probably because of the short interval in relation to the total time post-transplant. Although the symptoms score was strongly related to $\mathrm{FEV} 1 \%$ pred, RV/TLC \% pred and LCI, LCI was the sole predictor of SGRQ total score in multivariate analysis. This suggests that respiratory quality of life following 
HSCT may be affected by peripheral airway dysfunction as measured by ventilation heterogeneity in a global sense and is in keeping with similar findings with FOT [43]. The absence of correlation between Sacin and both SGRQ total score and the symptoms score in this longitudinal cohort with five out of the 22 patients with clinical BO, suggests that abnormalities in the more peripheral diffusion-dependent airway compartment are too peripheral to impact on respiratory symptoms.

In conclusion, the present study shows that impairment of peripheral airway function is related to time post-allogeneic HSCT, independently of spirometric signs of airflow obstruction and of respiratory symptoms, and that this impairment is related to cGVHD stage. The results of this cross-sectional study, along with findings from a limited period of follow-up testing, suggest that a prospective longitudinal study is warranted to determine whether MBNW is a potentially useful non-invasive method of monitoring peripheral airway function that could contribute to the clinical management of allogeneic HSCT recipients. If it proves to be a sensitive, early method with which to detect $\mathrm{BO}$, it would facilitate the exploration of novel therapies and strategies in HSCT-related BO.

\section{SUPPORT STATEMENT}

S. Lahzami was supported by Fondation SICPA, Fondation Andreas P. Naef pour la chirurgie thoracique, Fondation pour la recherche et le traitement des maladies respiratoires, and Société Académique Vaudoise. G.G. King was supported by a NH\&MRC Practitioner Fellowship. The study was supported in part by University of Sydney Bridging Grant U1089 and the Cooperative Research Centre for Asthma and Airways (project 2.1).

\section{STATEMENT OF INTEREST}

A statement of interest for G.G. King can be found at www.erj. ersjournals.com/site/misc/statements.xhtml

\section{REFERENCES}

1 Chien JW, Martin PJ, Gooley TA, et al. Airflow obstruction after myeloablative allogeneic hematopoietic stem cell transplantation. Am I Respir Crit Care Med 2003; 168: 208-214.

2 Chien JW, Martin PJ, Flowers ME, et al. Implications of early airflow decline after myeloablative allogeneic stem cell transplantation. Bone Marrow Transplant 2004; 33: 759-764.

3 Santo Tomas LH, Loberiza FR Jr, Klein JP, et al. Risk factors for bronchiolitis obliterans in allogeneic hematopoietic stem-cell transplantation for leukemia. Chest 2005; 128: 153-161.

4 Duncker C, Dohr D, Harsdorf S, et al. Non-infectious lung complications are closely associated with chronic graft-versus-host disease: a single center study of incidence, risk factors and outcome. Bone Marrow Transplant 2000; 25: 1263-1268.

5 Sakaida E, Nakaseko C, Harima A, et al. Late-onset noninfectious pulmonary complications after allogeneic stem cell transplantation are significantly associated with chronic graft-versus-host disease and with the graft-versus-leukemia effect. Blood 2003; 102: 4236-4242.

$6 \mathrm{Au} \mathrm{BKC}, \mathrm{Au} \mathrm{MA}$, Chien JW. Bronchiolitis obliterans syndrome epidemiology after allogeneic hematopoietic cell transplantation: prevalence, risk factors, and outcomes. Biol Blood Marrow Transplant 2011; 17: 1072-1078.

7 Yoshihara S, Tateishi U, Ando $\mathrm{T}$, et al. Lower incidence of bronchiolitis obliterans in allogeneic hematopoietic stem cell transplantation with reduced-intensity conditioning compared with myeloablative conditioning. Bone Marrow Transplant 2005; 35: 1195-1200.
8 Gunn MLD, Godwin JD, Kanne JP, et al. High-resolution CT findings of bronchioloitis obliterans syndrome after hematopoietic stem cell transplantation. J Thorac Imaging 2008; 23: 244-250.

9 Soubani AO, Uberti JP. Bronchiolitis obliterans following haematopoietic stem cell transplantation. Eur Respir J 2007; 29: 1007-1019.

10 Van Muylem A, Knoop C, Estenne M. Early detection of chronic pulmonary allograft dysfunction by exhaled biomarkers. Am J Respir Crit Care Med 2007; 175: 731-736.

11 Estenne M, Van Muylem A, Knoop C, et al. Detection of obliterative bronchiolitis after lung transplantation by indexes of ventilation distribution. Am J Respir Crit Care Med 2000; 162: 1047-1051.

12 Downie SR, Salome CM, Verbanck S, et al. Ventilation heterogeneity is a major determinant of airway hyperresponsiveness in asthma, independent of airway inflammation. Thorax 2007; 62: 684-689.

13 Verbanck S, Schuermans D, Paiva M, et al. Small airway function improvement after smoking cessation in smokers without airway obstruction. Am J Respir Crit Care Med 2006; 174: 853-857.

14 Verbanck S, Schuermans D, Meysman M, et al. Noninvasive assessment of airway alterations in smokers: the small airways revisited. Am J Respir Crit Care Med 2004; 170: 414-419.

15 Crawford $\mathrm{AB}$, Makowska M, Paiva $\mathrm{M}$, et al. Convection- and diffusion-dependent ventilation maldistribution in normal subjects. J Appl Physiol 1985; 59: 838-846.

16 Verbanck S, Schuermans D, Van Muylem A, et al. Ventilation distribution during histamine provocation. J Appl Physiol 1997; 83: 1907-1916.

17 Brown R, Woolcock AJ, Vincent NJ, et al. Physiological effects of experimental airway obstruction with beads. J Appl Physiol 1969; 27: $328-335$.

18 Goldman MD, Saadeh C, Ross D. Clinical applications of forced oscillation to assess peripheral airway function. Respir Physiol Neurobiol 2005; 148: 179-194.

19 King GG, Downie SR, Verbanck S, et al. Effects of methacholine on small airway function measured by forced oscillation technique and multiple breath nitrogen washout in normal subjects. Respir Physiol Neurobiol 2005; 148: 165-177.

20 Salome CM, Thorpe CW, Diba C, et al. Airway re-narrowing following deep inspiration in asthmatic and nonasthmatic subjects. Eur Respir J 2003; 22: 62-68.

21 Dellaca RL, Santus P, Aliverti A, et al. Detection of expiratory flow limitation in COPD using the forced oscillation technique. Eur Respir J 2004; 23: 232-240.

22 Walker PP, Hadcroft J, Costello RW, et al. Lung function changes following methacholine inhalation in COPD. Respir Med 2009; 103: 535-541.

23 Hamakawa H, Sakai H, Takahashi A, et al. Forced oscillation technique as a non-invasive assessment for lung transplant recipients. Adv Exp Med Biol 2010; 662: 293-298.

24 Dudek AZ, Mahaseth H, DeFor TE, et al. ; Bronchiolitis obliterans in chronic graft-versus-host disease: analysis of risk factors and treatment outcomes. Biol Blood Marrow Transplant 2003; 9: 657-666.

25 Marras TK, Chan CK, Lipton JH, et al. Long-term pulmonary function abnormalities and survival after allogeneic marrow transplantation. Bone Marrow Transplant 2004; 33: 509-517.

26 Rowlings PA, Przepiorka D, Klein JP, et al. IBMTR severity index for grading acute graft-versus-host disease: retrospective comparison with Glucksberg grade. Br J Haematol 1997; 97: 855-864.

27 Filipovich AH, Weisdorf D, Pavletic S, et al. National Institutes of Health consensus development project on criteria for clinical trials in chronic graft-versus-host disease: I. diagnosis and staging working group report. Biol Blood Marrow Transplant 2005; 11: 945-956.

28 Quanjer PH, Tammeling GJ, Cotes JE, et al. Lung volumes and forced ventilatory flows. Report Working Party Standardization of Lung Function Tests, European Community for Steel and Coal. Official Statement of the European Respiratory Society. Eur Respir J 1993; 6: Suppl. 16, 5-40. 
29 Crapo RO, Morris AH, Clayton PD, et al. Lung volumes in healthy nonsmoking adults. Bull Eur Physiopathol Respir 1982; 18: 419-425.

30 Pellegrino R, Viegi G, Brusasco V, et al. Interpretative strategies for lung function tests. Eur Respir J 2005; 26: 948-968.

31 Thorpe CW, Salome CM, Berend N, et al. Modeling airway resistance dynamics after tidal and deep inspirations. I Appl Physiol 2004; 97: 1643-1653.

32 Pasker HG, Mertens I, Clement J, et al. Normal values of total respiratory input resistance and reactance for adult men and females. Eur Respir Rev 1994; 4: 134-137.

33 Holm S. A simple sequentially rejective multiple test procedure. Scand J Statist 1979; 6: 65-70.

34 Lund $\mathrm{MB}$, Brinch L, Kongerud J, et al. Lung function $5 \mathrm{yrs}$ after allogeneic bone marrow transplantation conditioned with busulphan and cyclophosphamide. Eur Respir J 2004; 23: 901-905.

35 Barisione G, Bacigalupo A, Crimi E, et al. Changes in lung volumes and airway responsiveness following haematopoietic stem cell transplantation. Eur Respir J 2008; 32: 1576-1582.

36 Yokoi T, Hirabayashi N, Ito M, et al. Broncho-bronchiolitis obliterans as a complication of bone marrow transplantation: a clinicopathological study of eight autopsy cases. Nagoya BMT Group. Virchows Arch 1997; 431: 275-282.

37 Urbanski SJ, Kossakowska AE, Curtis J, et al. Idiopathic small airways pathology in patients with graft-versus-host disease following allogeneic bone marrow transplantation. Am J Surg Pathol 1987; 11: 965-971.

38 Chan CK, Hyland RH, Hutcheon MA, et al. Small-airways disease in recipients of allogeneic bone marrow transplants. An analysis of 11 cases and a review of the literature. Medicine (Baltimore) 1987; 66: 327-340.

39 Arens R, McDonough JM, Zhao H, et al. Altered lung mechanics after double-lung transplantation. Am J Respir Crit Care Med 1998; 158: 1403-1409.

40 Philit F, Wiesendanger T, Archimbaud E, et al. Post-transplant obstructive lung disease ("bronchiolitis obliterans"): a clinical comparative study of bone marrow and lung transplant patients. Eur Respir J 1995; 8: 551-558.

41 Oostveen E, MacLeod D, Lorino $\mathrm{H}$, et al. The forced oscillation technique in clinical practice: methodology, recommendations and future developments. Eur Respir J 2003; 22: 1026-1041.

42 Haddad IY, Panoskaltsis-Mortari A, Ingbar DH, et al. High levels of peroxynitrite are generated in the lungs of irradiated mice given cyclophosphamide and allogeneic T cells. A potential mechanism of injury after marrow transplantation. Am J Respir Cell Mol Biol 1999; 20: 1125-1135.

43 Haruna A, Oga T, Muro S, et al. Relationship between peripheral airway function and patient-reported outcomes in COPD: a crosssectional study. BMC Pulm Med 2010; 10: 10. 